\title{
Discovering domains - On the acquisition of causal connectives
}

\author{
Jacqueline Evers-Vermeul ${ }^{*}$, Ted Sanders \\ Utrecht Institute of Linguistics OTS - Utrecht University, Trans 10, NL-3512 JK Utrecht, The Netherlands
}

\section{A R T I C L E I N F O}

\section{Article history:}

Received 7 October 2009

Received in revised form 15 September 2010

Accepted 19 November 2010

Available online 28 December 2010

\section{Keywords:}

Child language

Discourse coherence

Dutch

Causality

Cumulative complexity

\begin{abstract}
A B S T R A C T
The acquisition of connectives (and, because, but) can be accounted for by the cumulative complexity approach - at least partially (Evers-Vermeul and Sanders, 2009). In this paper we extend this approach by distinguishing between several types of causal relations, such as Sweetser's (1990) content, epistemic and speech-act use of causal connectives. We used converging methodologies to investigate when children discover these three domains in the use of causal connectives. In two experiments, Dutch children aged 3;1-6;0 had to describe causally related events, argue with and instruct a hand puppet. These experiments revealed that even three-year-olds can produce causal connectives in all three domains. Our third study, a longitudinal corpus study among Dutch children aged $1 ; 6-5 ; 6$, shows that children as young as $2 ; 8$ are able to produce causal connectives in the content and the speech act domain, but that the epistemic domain is acquired later. Furthermore, it appears that context plays a crucial role in the production of domain types. Our approach of using converging methodologies proves fruitful: corpus-based data show us children's earliest spontaneous use and enable us to track longitudinal developments; experiments enable us to control for context effects.
\end{abstract}

(c) 2010 Elsevier B.V. All rights reserved.

\section{Introduction}

In everyday communication, people frequently speak about events they perceive in the real world and the way in which they evaluate these events. Events are often highly inter-related, and one important form of inter-relationship is causality. Acquiring the linguistic markers of causal coherence relations between utterances, causal connectives such as because and so, can be regarded as learning one of the most essential building blocks of language at the discourse level.

On the one hand, previous acquisition studies have shown that children younger than 7 or 8 make many mistakes in understanding all kinds of causal relations (cf. Piaget, 1930/1970; and the references in McCabe and Peterson, 1997:143), although Wing and Scholnick (1981) report almost errorless comprehension by first graders. On the other hand, few errors have been found in the spontaneous productions of because and so by children aged 2;6-3;6 (cf. Hood and Bloom, 1979; McCabe and Peterson, 1985). This raises the question as to whether this ease of producing causal connectives at a relatively young age holds for all types of causality or whether an acquisition order should be established for different kinds of causality.

It seems highly likely that different types of causality and their respective linguistic markers do not enter into the child's language at the same time. Several studies have shown that the relative complexity of linguistic elements and constructions influences the moment at which they appear in the child's language. For example, the idea that semantically simple words

\footnotetext{
* Corresponding author. Tel.: +31 30253 8125; fax: +31 302536000 .

E-mail address: j.evers@uu.nl (J. Evers-Vermeul).
} 
and grammatical constructions are acquired more easily than those that are semantically more complex is supported in several classical studies, for linguistic phenomena such as verbs (e.g. Clark, 1978), wh-questions (e.g. Bloom et al., 1982), and inflectional morphology (Brown, 1973).

Additional evidence in favor of an acquisition order in the area of causality is reported in Evers-Vermeul and Sanders (2009). For various languages, this longitudinal corpus study shows how organized the acquisition of coherence relations and connectives unfolds itself. Evers-Vermeul and Sanders develop a cumulative complexity approach, which can be regarded as a multi-dimensional elaboration of the explanation that Bloom et al. (1980:258) give for the uniformity in the development of coherence relations. It differs from the latter approach in that the defining conceptual notions are not ordered along one dimension (additive < temporal < causal < adversative). Instead, following Sanders et al. (1992, 1993), each connective is defined on the basis of several conceptual primitives that are of a general cognitive nature, such as polarity (positive versus negative) or relation type (additive versus causal). The cumulative complexity approach nicely explains why additive relations and connectives (and) are acquired before causal relations and connectives (because) and why positive relations and connectives (and) appear in child language before negative relations and connectives (but) do (cf. Spooren and Sanders, 2008).

Although this cumulative complexity approach adequately predicts the acquisition routes of these fundamentally different types of connectives and relations, it needs to be extended with additional conceptual primitives in order to give an account of the emergence of the whole range of connectives and coherence relations. For example, the current approach correctly predicts that causal connectives will appear only after additive ones have been acquired, but it does not predict anything about the acquisition order of different types of causality.

One of the fundamental distinctions that might be useful for a more refined cumulative complexity model is that causal relations can be construed in three different domains: content, epistemic and speech act (cf. Sweetser, 1990). ${ }^{1}$ The content example in (1) gives a description of a real-world causal relation: it shows Patricia's motivation for her act of going to Spain. The epistemic example in (2) is not a description of the real world, but it gives an argument for the child's claim that the train goes the wrong way, thereby illustrating the act of reasoning. The reason clause in (3) supports the illocutionary force of the first segment, in other words, it gives an argument for performing the imperative speech act.

Patricia gaat soms naar Spanje, want ze papa woont daar.

(Laura, 5;5.14)

'Patricia sometimes goes to Spain, because her (lit. his) father lives there.'

Child: $\quad$ Ja, hij (= de trein) gaat dan fout, hè.

(Matthijs, 3;6.3)

'Yes, it (= the train, lit. he) goes wrong then, doesn't it.'

Mother: Ja?

'Yes?'

Child:

want eigenlijk hoort ie zo te rijden.

'because actually it (lit. he) should drive this way.'

Niet zo hard, want anders kan ik niet werken.

(Laura, 4;9.10)

'Not so loud, because otherwise I cannot work.'

Sweetser's domain theory is well-known, but relatively little is known about the way children start using these domains. Therefore, two questions become relevant for the study of causal connectives in child language. First, when do children discover these different uses of causal connectives? Or, more precisely: when do children start producing causal connectives in each of these domains? A first glance at two previous studies in this field, Kyratzis et al. (1990) and Spooren and Sanders (2008), reveals two partially different acquisition orders. However, their results were gathered using quite different methods: Kyratzis and her colleagues performed a corpus-based study, whereas Spooren \& Sanders conducted an experiment. Therefore, we formulate a second research question: what do different research methods contribute to our knowledge in this area?

In section 2 we will discuss the findings of these two previous studies, to conclude that further research in this field is imperative. In sections 3, 4 and 5 we will present the results of two experiments and one corpus-based study which we conducted in order to get a clearer picture of the earliest stages of domain acquisition. We will conclude with some points for discussion and our conclusion.

\section{Review of and conclusions from the literature}

In this section we present a review of two earlier studies of causal connective acquisition, which are both valuable in their own respect. In section 2.1 we address Kyratzis et al.'s findings for English (1990); section 2.2 presents the Dutch results reported by Spooren and Sanders (2008). We will start with a summary of their findings and then focus on the methodologies

\footnotetext{
${ }^{1}$ Related distinctions were proposed in Sanders et al. (1992, 1993): Source of Coherence distinguishes between semantic (cf. content) versus pragmatic (epistemic and speech act) relations. We use Sweetser's more fine-grained distinction here, in order not to miss more subtle differences. In recent literature, it has been argued that subjectivity may be the underlying categorizing principle here, see, among others Sanders and Sweetser (2009).
} 
Table 1

Domain frequencies by age according to Kyratzis et al. (1990:209).

\begin{tabular}{lclrr}
\hline Age & Content & Epistemic & Speech act & Total \\
\hline $2 ; 4-3 ; 6$ & 0 & 0 & 4 & 14 \\
$3 ; 7-6 ; 6$ & 30 & 9 & 110 & 48 \\
$6 ; 7-12 ; 0$ & 16 & 1 & 40 & 197 \\
\hline
\end{tabular}

and the operationalizations that are used in these studies. Our goal is to show how methodological choices might have affected the outcomes reported in each study. A preliminary conclusion in section 2.3 will show the need for further research into the acquisition of domains.

\subsection{A study of causal connectives in English conversation}

Kyratzis et al. (1990) (henceforth KGE) analyzed data from 21 English children aged 2;4-12;0 in the 1976 Ervin-Tripp family corpus. This corpus is composed of natural family interactions recorded in the home, and involves activities such as having lunch and playing tea party. KGE focused on the acquisition of the causal connectives because and so. On the basis of the quantitative data in Table 1, they claim that very young children only use because and so to mark speech-act relations, and that later on the content use of these connectives increases. ${ }^{2}$ Epistemic use is very infrequent, and remains so throughout the age period studied here.

KGE (p. 210) conclude: "It appears that children first learn causals as realizing one particular pragmatic function, that of justifying speech acts, and only later, with development, acquire a broader range of pragmatic functions for their causal constructions - their function of explaining events described in propositions and their function of justifying conclusions." KGE explain this order of acquisition by referring to the fact that children generally want to achieve what they want and that speechact relations are the most convenient way to do so. This explanation can be regarded as a social-pragmatic complexity approach: the more useful a certain connective use is in the life of a child, the easier it is to acquire that connective use.

KGE chose a corpus-based approach. A first advantage of this approach is that it shows us naturalistic data in their actual context of usage. Second, corpora enable researchers to track longitudinal changes and to take into account data from very young children: KGE analyzed the causal language of children as young as 2;4. Third, a corpus-based approach is perfectly suitable for pinpointing individual differences in the course of acquisition, although KGE have chosen to mention grouped frequencies instead of individual data.

Taking a corpus-based approach has certain drawbacks as well, especially in the case of causal connectives and other linguistic elements that are in a sense optional. In contrast to obligatory elements in syntax or morphology, such as determiners or markers of subject-verb agreement, causal connectives are not a necessary component of grammatical clauses. This can sometimes result in relatively low numbers of occurrences for a certain recording period, which makes it difficult to draw firm conclusions: the lack of connectives might indicate children's inability to produce them (in a certain domain), or just a preference for leaving (that specific type of) causal coherence relations unmarked. We do not know whether the latter option holds true for KGE's study, but we do know that the claim about speech-act relations occurring first is based on a very small number of observations: only four cases in a recording period that lasts over a year (see Table 1).

Another consequence of KGE taking a corpus-based approach is that the numbers per domain may have suffered from effects of context. More specifically, the number of speech-act uses is probably inflated in KGE's study due to context effects. This bias for speech-act relations in conversations during plays and during dinner can be inferred from the following remark in KGE (p. 210): "a preliminary analysis of the adults' uses of causals in this corpus revealed that a vast majority were also Speech Act-Level Causals."

Not only the choice of the research method might affect the outcome of the study, but also the operationalization or definition of various notions in the study. For instance, in order to count the number of causal connectives in different domains, KGE (p. 210) considered causal utterances in which the child produced both the antecedent and the consequent clause, and excluded responses to why-questions. This operationalization seems fine if one wants to draw conclusions about child utterances that are produced both spontaneously and completely independent of the parents. However, from a developmental perspective it seems interesting to look at utterances children produce in reaction to others as well. Other studies into the acquisition of English causal connectives (cf. Braunwald, 1997; McCabe and Peterson, 1997; Diessel, 2004) have shown that children's earliest instances of because are often restricted to occurrence in responses to why-questions, and that children only later on develop the ability to produce because-clauses in more spontaneous ways. For example, in (4) Abel comes up with a suitable answer to the investigator's why-question. ${ }^{3}$

$$
\text { Investigator: } \quad \text { Is dat niet een beetje gevaarlijk, een tijger? }
$$

'Isn't that a bit dangerous, a tiger?'

\footnotetext{
${ }^{2}$ The numbers in Table 1 are inferred from the percentages mentioned in Kyratzis et al. (1990:209, see their Table 1).

3 At least, from a pragmatic perspective. From a lexical perspective, the answer is not optimal. Abel could have chosen a more appropriate causal connective: the subordinator omdat instead of the coordinator want.
} 

Abel:
Eh nee.
'Uhm no.'
Investigator:
Nee, waarom niet?
'No, why not?'
Abel:
Eh want de tijger is lief.
'Uhm because the tiger is nice.'

(Abel 3;4.1)

KGE would classify Abel's connective utterance as incomplete and therefore dismiss it in their analysis. Still, children who are capable of answering why-questions can be considered as children who have started to use causal connectives properly. Therefore, it is interesting and informative to include answers to why-questions in more extensive analyses.

Another reason for choosing a more lenient operationalization when charting children's connective development lies in the incremental nature of spoken discourse as well as in children's development in clause integration (Diessel, 2004). Previous studies have revealed that very young children only explicate causal links across utterance boundaries, and often also across speaker turns (cf. Diessel, 2004:158; Evers-Vermeul, 2005). For example, in (4) Abel first denies the investigator's remark, which results in the implicit antecedent 'a tiger is not dangerous'. Only in his next turn does he supplement this antecedent with a consequent 'because the tiger is nice'. Probably, KGE would classify Abel's connective utterance as incomplete. In fact, the majority of causals produced by the youngest age group in their study and one third of the causals of the intermediate group are classified as incomplete, and hence disregarded in the analysis. Hence, the exclusion of whyquestions from KGE's analysis may have resulted in an underrepresentation of children's connective use. More importantly, it may have deflated the number of content relations, especially in the data of the youngest children, because why-questions are known to frequently trigger content relations. For example, why-questions may ask for reasons to perform certain actions during a play. If one would like to take children's less spontaneous causal connective use into account, it appears that the selection criterion set by KGE results in an underestimation of young children's abilities in terms of domains. ${ }^{4}$

All in all, the corpus-based study by Kyratzis et al. has generated several valuable insights, especially in children's connective use in utterances that are produced without parental intervention. However, our understanding of causal connective acquisition can be broadened by using different methods and by taking into account causal utterances that arise in interaction with parents and other conversational partners.

\subsection{An experimental study of causal connectives and coherence relations in Dutch}

The English findings of KGE are partially in contrast with the Dutch results reported in Spooren and Sanders (2008) (henceforth S\&S). S\&S performed a corpus-analytic study under experimental control using Dutch children as informants. Their research was carried out with elementary school children from different age groups: six children from grade 1 (age 6 -7) and six from grade 6 (age 11-12). The children were given two tasks, both aiming at eliciting clause combinations that expressed a causal coherence relation. In the description task, which biased for content relations, children had to describe pictures that showed large numbers of causally related events. In the conversation task, which biased for epistemic and speech-act relations, the children had to formulate their opinion on a number of controversial topics, such as vetoed TV programs and the amount of children's pocket money (S\&S, p. 2011).

In their analysis, S\&S did not focus on causal connectives alone, but looked at causal coherence relations in general. This avoids the risk of encountering small numbers of connectives due to their non-obligatory character (see the previous section). The results of their study were as follows (S\&S, p. 2014). Summed over both tasks, the younger children produced more content relations than the older children. Within the non-content relations, the speech-act use predominated. However, the two age groups did not differ in their numbers of epistemic and speech-act relations. The data showed a significant influence of context on the occurrence of different domains: in the conversation task children produced more epistemic and speech-act relations. For example, in the epistemic relation in (5), Chantal concludes that a possible explanation for the mummy walking around is that someone opened the coffin (example taken from S\&S, p. 2024). In the description task the content domain prevailed. For instance, in the content relation in (6), Daan presents a cause-consequence relation between two facts that can be observed in the picture he has to describe (example taken from S\&S, p. 2006).

[Chantal points to a mummy walking around; in the corner of the picture there is an open coffin.]

Daar komt een mummie. Misschien hebben ze de kist opengedaan.

(Chantal, 12;6)

'There comes a mummy. Maybe they opened the coffin.'

Daar leunt een dikke man tegen een paal

en daardoor vallen de blokken van de paal om.

(Daan, $11 ; 11$ )

'There is a fat man leaning against a post

and because of that the building blocks of the post fall down.'

\footnotetext{
${ }^{4}$ Spooren and Sanders (2008) apply the same criterion, but the impact is less drastic in their study, since the production of causal utterances by children aged six and older is less dependent on the occurrence of why-questions.
} 
S\&S take their results as an indication that content relations are acquired before non-content relations. They claim that it is the cognitive or conceptual complexity that determines this order in the acquisition of different coherence relations and the connectives expressing them. According to them (see also Sanders et al., 1993), epistemic relations are more complex than content relations, "as they require abstract reasoning, usually exploiting relations that exist between real world events" (S\&S, p. 2009).

Taking an experimental approach has an important advantage. S\&S have clearly shown that the type of relations children produce indeed depends on the communicative task: in the conversation task children produced more non-content relations, and in the description task the content domain prevailed (cf. also Sanders, 1997). This influence of task type is also reported in Shapiro and Hudson (1997:42): "The level of narrative skill that children demonstrate can be increased or decreased by providing them with more or less difficult tasks. Moreover, the structure of the story that they are telling (i.e. the degree of causal complexity) will affect the types of interclausal devices they employ, independent of their general ability to use these markers." Relating this task effect to the difference in KGE's and S\&S' findings, the seemingly contradictory results with respect to the acquisition of domains "may be attributable to a difference in context in which the data were collected" (S\&S, p. 2011).

The experimental approach taken by S\&S (2008) not only shows that context should not be neglected in research into the discovery of domains, but also that it is possible to manipulate the communicative context in such a way that children produce spontaneous utterances in a quasi-experimental setting.

Also, specific choices in the operationalization may have affected the outcome of this experiment. A consequence of the task choice in the Dutch study is that their conversational tasks hardly caused the children to produce motivated interrogatives or imperatives. Hence, S\&S' speech-act category mainly included motivated assertions such as (7) (example taken from S\&S, p. 2024).

En Sesamstraat vind ik niet meer zo leuk. Want daar ben ik nu te groot voor.

(Rose, $12 ; 3$ )

'And I don't like Sesame Street very much anymore. Because I'm too old for that now.'

In contrast, Kyratzis and colleagues only included justified interrogatives, direct or indirect imperatives, and responses in their category of speech acts. In their study, this category contained hardly any matrix clauses with the form of an assertion or a declarative (cf. KGE, p. 208). This difference between the two studies makes us wonder whether we have obtained a full picture of the acquisition of speech-act relations. A probable explanation for the difference - apart from context effects - is that S\&S restricted their epistemic category to relations involving the generation or inference of new knowledge (see their Appendix C). The remaining motivated assertions were labeled as speech-act relations. For example, the relation in (5) is considered epistemic, because it presents a conclusion of the speaker in the "here and now". In contrast, the relation in (7) is categorized as a speech-act relation, since it conveys existing instead of new knowledge. It is analyzed as "I say that I do not like Sesame Street very much anymore and the reason for me saying that is that I am too old for it now". The "here and now" restriction applied to the epistemic category has probably resulted in a deflated number of epistemic relations and an inflated number of (assertive) speech acts.

A final issue concerning the operationalization of the experiment concerns the age range of the children under investigation: S\&S studied children aged six or older. It turned out that even the youngest children in their study had already acquired all three domain types. As a result, the data simply do not allow for direct conclusions about an order of acquisition. S\&S use the technique of implicational scaling to derive an acquisition order: the rank orders of the domains - in terms of frequency - are equated to the acquisition sequence of these domains. However, a higher frequency of a certain domain at a later age does not necessarily imply that this domain is acquired first (see Klein Gunnewiek, 1999:52 for some additional critical remarks on this technique). As S\&S (p. 2020) suggest themselves, "the utterances of younger children should be studied to find the kind of differences under discussion."

\subsection{Preliminary conclusion from the literature}

The two existing empirical studies discussed above, reported different orders of domain acquisition. KGE found that speech acts appeared first in child language, but they collected their longitudinal data in a conversational context that was biased towards speech acts. In addition, they excluded certain causal utterances from their analysis, which probably deflated the number of content relations in the data of the younger children. S\&S, on the other hand, claimed that content relations emerge first, but their data were collected in an experiment among children aged six or older, and therefore provide only indirect evidence for this acquisition order.

These factors indicate that charting the discovery of domains is a complex matter, and that additional research using different methodologies and operationalizations is necessary in order to expand our knowledge in this area, especially the early stages of domain discovery. In the current study, we will present the results of three studies that were carried out to shed more light on the acquisition of domains. Section 3 discusses an experiment that was conducted to find out whether four-year-old Dutch children are able to produce epistemic relations. Section 4 reports on a follow-up experiment in which Dutch children as young as three were triggered to produce causal coherence relations in the content, speech-act, as well as in the epistemic domain. Section 5 introduces a domain analysis of the longitudinal data of twelve Dutch children in the CHILDES-database. This analysis was carried out to find out the order in which the three domains emerge in Dutch child language and to give a more detailed picture of the domains acquisition of four Dutch causal connectives. 


\section{A first experiment on Dutch: epistemic late?}

The data reported in KGE and S\&S indicate that epistemic relations are acquired relatively late. The younger children in the English study hardly produced any epistemic causal relations. The Dutch study revealed that six-year olds were able to come up with epistemic relations, but that neither six-year olds nor twelve-year olds produced them frequently. This raises the question as to whether the late occurrence of epistemic relations is really due to their relative complexity, or whether the two previous studies just did not contain the right contexts. This latter option is plausible, since in both acquisition studies the numbers of epistemic relations were deflated due to independent reasons. In order to find out whether young children are indeed unable to produce epistemic relations, we conducted an experiment among Dutch children aged four and five. The materials, participants and analytical method of this study are accounted for in section 3.1; the results are presented in section 3.2.

\subsection{Materials, participants and analytical method}

There is a relationship between text type and the type of coherence relations, such as epistemic versus content relations; research shows that descriptive discourse, like encyclopedic texts are dominated by content relations, whereas subjective relations are more important, both in number and in hierarchical position, in persuasive texts like advertisements (Sanders, 1997; Taboada and Mann, 2006). For this reason, we conducted a study in which we systematically varied the communicative context in which children were invited to speak: they were presented with an argumentative task and a directive task. This way, chances of finding epistemic and non-assertive speech act relations were maximized.

Each child was given two 10-min tasks: an argumentation task with a bias for epistemic relations, and a directive task that was biased for relations in the speech-act domain. In the argumentation task children had to select their favorite teacher, friend or athlete out of a set of four pictures and then convince a hand puppet why this was the right choice. In the directive task children were told that they were the teacher of hand puppet Ernie and that they had to instruct the hand puppet where to put certain stickers on a picture. Because Ernie was very naughty, they had to motivate why the puppet should put it there and not somewhere else on the picture.

The investigation was carried out with five children from groep 1 'pre-kindergarten' and five children from groep 2 'kindergarten' of an elementary school in a medium-sized town in the southwest of the Netherlands. The ages of the children in the first group varied from $4 ; 7$ to $4 ; 11$. The ages of the children in the second group varied from 5;5 to 6;5. All children were native speakers of Dutch and were interviewed individually in a separate room of the elementary school they attended.

The children's utterances were recorded on a cassette recorder and transcribed. The unit of transcription and analysis was the clause. In addition to complete clauses (containing a verb), we took into account answers to yes/no-questions as well as contracted clauses that would be considered grammatical in adult Dutch. For each clause it was decided whether it could be linked to another clause, and if so, whether it should be linked in an additive or a causal way (cf. the basic operation in Sanders et al., 1992). Using a paraphrase test, we categorized all the causal utterances in terms of domains. For ease of comparison, the definitions of the epistemic and the speech-act category were the same as in S\&S. ${ }^{5}$ Epistemic relations concern relations between arguments and conclusions in which the generation or inference of new knowledge is central. For example, in (8) Danny selects his favorite teacher, providing an argument why this teacher is nice. Speech acts can be paraphrased as "I order you, ask you... (etc.): first clause. The basis for my speech act is that: second clause.” In (9) Hugo's first clause directs the hand puppet to put the cloud in the sky; his second clause provides a rationale for this speech act.

Deze is een leuke meester, omdat 'ie leuke schoenen aan heeft.

(Danny, 5;11)

'This is a nice teacher, because he is wearing nice shoes.'

Pak de wolk 'es. Leg 'm 'es in de lucht, omdat de wolken altijd in de lucht horen.

(Hugo, 5;11)

'Grab the cloud. Put it in the sky, because clouds always belong in the sky.'

The frequencies of use in the epistemic and the speech-act domain were calculated per task and per group and analyzed statistically using a logit analysis (see Appendix A). In this analysis, the frequencies per domain were related to the total number of utterances per age group (448 for group 1, and 518 for group 2).

\subsection{Experimental results and conclusions}

The children produced 156 spontaneous causal coherence relations. These included four causally related utterances in which the first clause was not expressed by the child, but by the investigator. An additional number of 27 relations was produced after why-questions or elicited otherwise. The frequencies of the domains produced by the two age groups are presented in Table 2 . In both domains, coherence relations were frequently marked with a suitable connective: on average, $60 \%$ of the spontaneously produced relations contained a connective (64\% group $1 ; 54 \%$ group 2 ).

\footnotetext{
${ }^{5}$ The choice of these definitions instead of KGE's ones did not affect the results in a significant way. The children mainly produced speech-act relations that included imperatives. There were hardly any declaratives in the speech-act category, because the argumentative task forced the children to draw new conclusions instead of reporting old ones.
} 
Table 2

Frequencies of spontaneously produced domains (+elicited usage) per task per group.

\begin{tabular}{|c|c|c|c|c|c|}
\hline & \multicolumn{2}{|c|}{ Directive task } & \multicolumn{2}{|c|}{ Argumentative task } & \multirow[t]{2}{*}{ Total } \\
\hline & Group 1 & Group 2 & Group 1 & Group 2 & \\
\hline Epistemic & $10(+2)$ & $2(+0)$ & $31(+2)$ & $45(+3)$ & $88(+7)$ \\
\hline Speech act & $31(+7)$ & $19(+11)$ & $12(+1)$ & $6(+1)$ & $68(+20)$ \\
\hline Total & $41(+9)$ & $21(+11)$ & $43(+3)$ & $51(+4)$ & $156(+27)$ \\
\hline
\end{tabular}

Table 2 shows that children aged four and five (group 1) are able to relate clauses in an epistemic way. In the argumentative task, the children produced more epistemic than speech-act relations spontaneously $\left(\chi^{2}(1)=63.5 ; p<.001\right)$. Indeed, the argumentative task often resulted in epistemic utterances such as (10), whereas the directive task mainly triggered speech-act utterances such as (11). Furthermore, group 2 produced more epistemic relations in the argumentative task than group $1\left(\chi^{2}(1)=5.6 ; p<.03\right)$, which indicates that the ability to produce epistemic relations increases with age.

Vind ik toch niet leuk, want die is aan het poetsen.

'I don't like that one after all, because he is brushing his teeth.'

Hier leggen. Ja, want dan zitten de kikkers eigenlijk in het water.

'Put it here. Yes, because then the frogs are actually in the water.
(Inge, 5;5)

(Kelly, 4;11)

In this study, the influence of the experimenter could not be ruled out completely. Because children did not always provide a reason spontaneously, the experimenter sometimes urged the child to do so by asking why-questions. For example, in (12), Michael does not motivate his choice of a specific picture spontaneously, but does so in response to a why-question uttered by the experimenter. Similarly, Dennis only supports his speech act in (13) after being urged to do so by the investigator. In our statistical analysis, we excluded these cases - 12 in group 1 and 15 in group 2 - and only took those coherence relations into account that were produced spontaneously. Hence, we can state that our results slightly underestimate the abilities of the children, since answering why-questions in a proper way presupposes the knowledge how to produce a causal coherence relation.

Investigator:

Child:

Investigator:

Child:

(13) Child:

Hand puppet Ernie:

Child:

Hand puppet Ernie:

Investigator:

Child:
Wie kan nou het beste voetballen?

We moeten ook zeggen waarom natuurlijk.

'Well, who can play soccer best? We also have to say why, of course.'

Deze.

(Michael, 6;4)

'This one.'

Vertel Ernie maar 's waarom je die dan het beste vindt.

'Tell Ernie [the hand puppet] why you think that one is the best.'

Want die ken hard rennen.

'Because he can run fast.'

Pak de zon en leg die in de lucht.

(Dennis, 5;5)

'Take the sun and put it in the sky.'

Nee, ik doe het niet. Ik pak de zon en ik leg hem op zijn hoofd, want dan krijg 'ie een heel warm hoofd.

'No, I won't do that. I take the sun and put it on his head, because then he will get a very warm head.'

Leg de zon in de lucht!

'Put the sun in the sky!'

Maar een heet hoofd is leuk!

'But I like a hot head.'

Vertel maar goed waarom die in de lucht moet, hoor.

'Just tell him why it has to go in the sky.'

Anders gaat het regenen en dat vinden de mensen niet leuk.

'Otherwise it will rain and people don't like that.'

The experimental data confirm the influence of context on the occurrence of domain types. In addition, they reveal that children's development in terms of domains takes place before the age of four. Children as young as four are capable of producing epistemic relations - and marking them with causal connectives - when they have incorporated the 
communicative goal of persuading someone, which is the case in an argumentative context. These findings imply (a) that the debate on the acquisition order of the domains should not be restricted to the content and the speech-act domain, and (b) that children below the age of four should be studied in order to decide which domain of use emerges first. In section 4 , then, we will present the results of a second experiment, conducted with Dutch children aged three and four.

These findings suggest there are several advantages to applying an experimental approach in this research area. First, it allowed us to take context effects into account. Although this specific experiment did not provide a context in which the content use of connectives was elicited, we have shown that children are sensitive to the communicative context, and that they are able to adapt their language use accordingly. Second, we have shown that it is possible to conduct the experiment with children as young as four.

\section{A second experiment on Dutch}

Because our first experiment revealed that younger children should be studied in order to answer our research question, we conducted a second experiment in order to obtain a picture of the acquisition order of the three domains. This experiment was highly similar to the first experiment, but we extended it with a context that elicited relations in the content domain. The materials, participants and analytical method of this study are accounted for in section 4.1; the results are presented in section 4.2 .

\subsection{Materials, participants and analytical method}

Each child was given three short tasks: a descriptive task with a bias for content relations, a directive task that was biased for relations in the speech-act domain, and an argumentation task with a bias for epistemic relations. In the descriptive task, the hand puppet Ernie asked the child to describe sets of pictures to his blindfolded friend Bert. Each set of pictures showed three events that could be related in a causal way. For example, the set in Fig. 1 shows a happy girl with a balloon, who turns into a sad girl because she let go of the balloon. Each child was presented one practice set and four sets of test items.

The directive task was similar to the one in the first experiment, except that children were given a set of Nijntje Viltschilderijen 'Miffy's felt pictures' instead of sets of stickers. These materials were chosen because most Dutch children are very familiar with the character Nijntje 'Miffy', created by Dick Bruna in 1955. Each child was presented with two different felt backgrounds (living room, farm, or beach) and was told to instruct hand puppet Ernie where to put certain felt figures (such as a cow or a kite), motivating the instruction because Ernie was naughty. The argumentation task was also similar to the one in the first experiment. However, this time children had to select an object rather than a picture out of a set of four (e.g. four toys, puzzles, or presents). This increased the attractiveness of the task and enlarged the argumentative space. Again, one practice set and four sets of test items were presented.

The investigation was carried out with twelve Dutch children who attended a daycare in Utrecht, the Netherlands. The ages of the seven children in the first group varied from 2;9 to 3;4 (mean age 3;1). The ages of the five children in the second group varied from 3;9 to 4;4 (mean age 4;0). All children were native speakers of Dutch and were interviewed individually in a separate room of the daycare they attended.

The children's utterances were recorded on a cassette recorder and transcribed. Then, they were analyzed using the same criteria as in the first Dutch experiment. For each causal coherence relation, we determined the domain and checked whether it was uttered spontaneously or in response to a why- or how come-question. The frequencies of use in the content, the epistemic and the speech-act domain were calculated per task and per group and analyzed statistically using a logit analysis
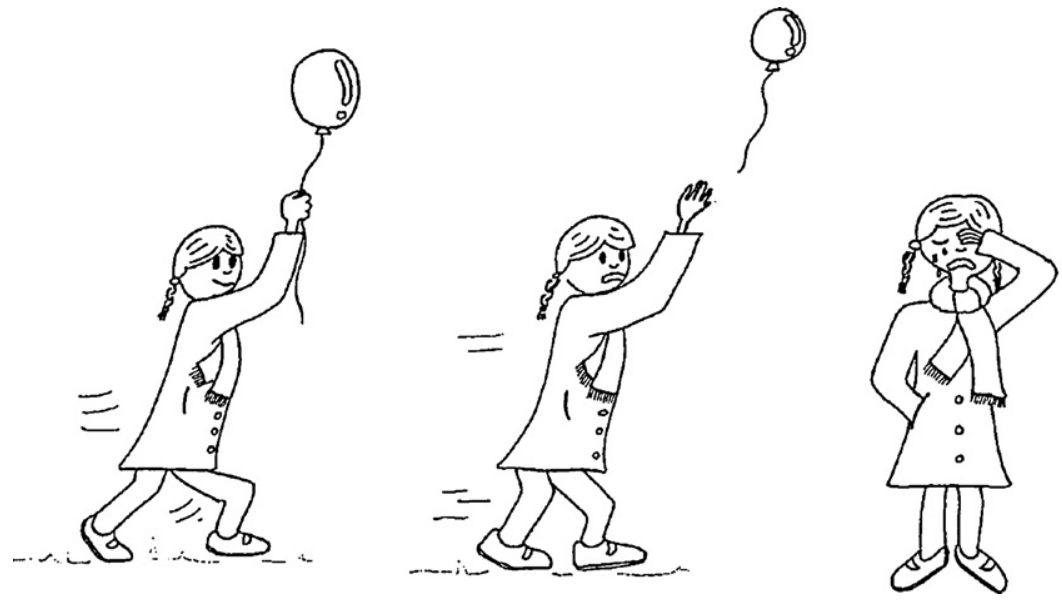

Fig. 1. Example of materials used in the descriptive task in experiment 2. 
Table 3

Frequencies of spontaneously produced domains (+elicited usage) per task per group.

\begin{tabular}{|c|c|c|c|c|c|c|c|}
\hline & \multicolumn{2}{|c|}{ Descriptive task } & \multicolumn{2}{|c|}{ Directive task } & \multicolumn{2}{|c|}{ Argumentative task } & \multirow[t]{2}{*}{ Total } \\
\hline & 3-year-old & 4-year-old & 3-year-old & 4-year-old & 3-year-old & 4-year-old & \\
\hline Content & $15(+12)$ & $14(+25)$ & $3(+3)$ & $0(+0)$ & $1(+0)$ & $1(+1)$ & $34(+41)$ \\
\hline Epistemic & $1(+1)$ & $1(+0)$ & $1(+3)$ & $5(+0)$ & $11(+11)$ & $2(+23)$ & $21(+38)$ \\
\hline Speech act & $0(+0)$ & $0(+0)$ & $16(+37)$ & $24(+62)$ & $0(+0)$ & $0(+0)$ & $40(+99)$ \\
\hline Total & $16(+13)$ & $15(+25)$ & $20(+43)$ & $29(+62)$ & $12(+11)$ & $3(+24)$ & $95(+178)$ \\
\hline
\end{tabular}

(see Appendix B). In this analysis, the frequencies per domain were related to the total number of coherence relations per age group (203 for the 3-year-olds, and 228 for the 4-year-olds).

\subsection{Experimental results and conclusions}

The children produced a total amount of 273 causal coherence relations. These included 162 causally related utterances in which the first clause was not expressed by the child, but by the investigator. The frequencies of the domains produced by the two age groups are presented in Table 3. This table shows that the majority of the relations was elicited by the investigator (178 elicited versus 95 spontaneously uttered relations). The children in group 1 marked 38\% of their spontaneously produced coherence relations with a suitable connective; group 2 added a connective in $72 \%$ of the cases.

Table 3 reveals that even three-year-olds are able to relate clauses in an epistemic way, although both three- and fouryear-olds produce fewer epistemic relations than relations in the other two domains $\left(\chi^{2}(2)=41.5 ; p<.001\right)$. Again, we found a strong effect for context on the occurrence of the different domains $\left(\chi^{2}(4)=435.0 ; p<.001\right)$ : in the descriptive task children mainly produced content relations such as (14), the directive task predominantly triggered speech acts (as in (15) and (16)), and the argumentative task often resulted in epistemic relations such as (17) and (18).

En toen was de ballon helemaal weg. En toen was ze helemaal verdrietig.

(Freek, 3;4)

'And then the balloon was all gone. And then she was very sad.'

Die (bal) moet op het strand. Want daar is iemand.

(Arne, 3;11)

'That (ball) should go on the beach. Because there is someone.'

Nee! Hier moet toch ook vol!

(Laura, 2;9)

'No (= don't put it there)! It should become full here as well!'

Die is nog een baby. Oh die is nog heel klein. Daarom geeft ik die boek.

(Laura, 3;3)

'She is just a baby. Oh she is very small. That's why I give that book.'

Deze (puzzel) is wel een beetje moeilijk hoor.

Want die kijk zitten allemaal puzzels bij.

(Margot, 3;3)

'This (puzzle) is a bit difficult. Because look, there are all "puzzles" to it.'

There is no three-way interaction between age, task and domain $\left(\chi^{2}(4)=7.5 ; p=.11\right)$. That means that the three- and fouryear-old children do not differ in the amount of relations they produce per task.

Just as in our first experiment, the influence of the experimenter could not be ruled out. The experimenter was instructed to refrain from asking why-questions as much as possible, but in order to keep the interaction going, and because she wanted to be friendly to the children, she asked several how come-questions instead. Fortunately, this interference did not affect the results in a significant way: the distribution of the domains over groups and tasks remains the same if only children's spontaneous causal utterances are taken into account. The fact that children often responded properly to the investigator's questions also shows that they are indeed capable of producing the relevant relations.

The findings of this second experimental study imply that children below the age of three should be studied in order to decide which domain of use emerges first. In section 5 , then, we will present a longitudinal study into the domain acquisition of causal connectives by Dutch children aged two and older.

\section{Longitudinal study of Dutch}

In order to provide natural data on the Dutch acquisition order of the three domains, we examined the transcripts of the spontaneous speech of twelve very young Dutch children. All these materials are available through the Child Language Data Exchange System or CHILDES (MacWhinney, 2000). The transcripts in these longitudinal corpora are based on audiotape recordings made at home, in an unstructured home setting. Most children were recorded from the age of 2;0 till the age of 3;6, comparable to the ages of the youngest group in KGE's study (see Table 4, which also shows the total number of utterances produced by each child). 
Table 4

Dutch corpus data (with ages in years;months.days).

\begin{tabular}{|c|c|c|c|}
\hline Child & Age range & Number of utterances & Corpus \\
\hline Abel & $1 ; 10.30-3 ; 04.01$ & 11,883 & Groningen (Bol, 1996) \\
\hline Daan & $1 ; 08.21-3 ; 03.30$ & 15,229 & Groningen \\
\hline Hein & $2 ; 04.11-3 ; 01.24$ & 12,781 & Utrecht (Elbers and Wijnen, 1992) \\
\hline Iris & $2 ; 01.01-3 ; 06.15$ & 8771 & Groningen \\
\hline Josse & $2 ; 00.07-3 ; 04.17$ & 12,651 & Groningen \\
\hline Laura & $1 ; 09.04-5 ; 06.12$ & 22,323 & Van Kampen (1997) \\
\hline Matthijs & $1 ; 10.13-3 ; 07.02$ & 19,864 & Groningen \\
\hline Niek & $2 ; 07.00-3 ; 10.17$ & 15,151 & Wijnen (Elbers and Wijnen, 1992) \\
\hline Peter & $1 ; 05.09-2 ; 08.22$ & 8578 & Groningen \\
\hline Sarah & $1 ; 06.16-5 ; 02.13$ & 17,458 & Van Kampen \\
\hline Thomas & $2 ; 03.22-2 ; 11.22$ & 12,670 & Utrecht \\
\hline Tomas & $1 ; 07.05-3 ; 01.02$ & 9126 & Groningen \\
\hline
\end{tabular}

Table 5

Characteristics of four Dutch connectives.

\begin{tabular}{llll}
\hline Connective & Translation & Syntax & Direction of causality \\
\hline Want & Because, for & Coordinator & Backward \\
Omdat & Because & Subordinator & Bpistemic \\
Dus & So & Adverb & Forward domain \\
Daarom & That's why & Adverb & Forward \\
\hline
\end{tabular}

In our experimental studies, we did not differentiate our findings according to connective choice. Therefore, it was not necessary to consider specific properties (such as syntax) of the connectives. However, it is important to note that the Dutch language has four connectives that are frequently used to mark causal coherence relations and that differ in several respects: want 'because', omdat 'because', dus 'so', and daarom 'that's why'. A more detailed analysis of the domain acquisition per connective appears to be a promising undertaking. First, because these connectives differ in their syntax. Dus and daarom are adverbials, want is a coordinator used in clauses with a verb second word order typical of Dutch main clauses, and the subordinator omdat occurs in clauses with a verb final word order typical of Dutch subordinate clauses. Second, both want and omdat mark backward causal relations (consequence-cause), whereas dus and daarom mark forward (causeconsequence) relations. Third, in adult language, the connectives show different domain preferences: want and dus often occur in epistemic relations, whereas omdat and daarom frequently show up in content relations (cf., among others, Pit, 2003; Evers-Vermeul, 2005; Stukker, 2005). Table 5 presents an overview of the characteristics of the four connectives. ${ }^{6}$

For each child, every utterance with one of these causal connectives was selected by using Computerized Language Analysis (CLAN) (MacWhinney, 2000). In our analyses, we included connective clauses that were causally linked to utterances from the children themselves or to utterances from their parents, including why-questions, but excluded direct imitations and other non-creative utterances. We established the distribution of the connective fragments over the domains on the basis of a paraphrase test (Sanders, 1997; Evers-Vermeul, 2005). The definitions in this paraphrase test were highly similar to the ones used by Kyratzis et al. (1990). It differed from S\&S' operationalization in that the speech-act category was restricted to non-assertive speech acts (e.g. questions, directives), and that the epistemic category included both new and older conclusions (opinions, judgments, claims about the desirability, etc.). Example (19) presents a content relation: Josse motivates his action of putting a toy wheel in the kitchen drawer by referring to the fact that it was broken. In (20) Hein justifies his mother's directive with a want-clause (a speech-act causal), and in the epistemic example (21) Abel - who has trouble using the words brother and sister correctly - provides a reason for his conclusion that Lotte is a girl, although he mixes up the gender of the pronoun.

(19) Mother: Waar heb je dat wiel nu gedaan, van die motor?

'Where did you put that wheel, of that motor?'

Child: $\quad$ Die is in de la.

(Josse, 3;1.24)

'It is in the drawer.'

Mother: $\quad$ In de la, in de keukenla?

'In the drawer, in the kitchen drawer?'

Child: $\quad$ Ja, want die was stuk.

'Yes, because it was broken.'

\footnotetext{
${ }^{6}$ Dutch want is similar to English for in its syntactic characteristics, but it is not as formal as for (Evers-Vermeul, 2005).
} 
Table 6

Distribution of Dutch and English connective utterances over the domains

\begin{tabular}{llcccc}
\hline Language & Age range & Content & Epistemic & Speech act & Uninterpretable \\
\hline Dutch & $1 ; 6-3 ; 6$ & 29 & 23 & 41 & 63 \\
English & $2 ; 4-3 ; 6$ & 0 & 0 & 4 & 156 \\
\hline
\end{tabular}

Table 7

Orders of emergence of the three domains in connective utterances.

\begin{tabular}{|c|c|c|c|c|}
\hline \multirow[t]{2}{*}{ Number of children showing this order } & \multicolumn{3}{|l|}{ Order of emergence } & \multirow[b]{2}{*}{ Not acquired } \\
\hline & 1 & 2 & 3 & \\
\hline 3 & Content & & & Speech act, epistemic \\
\hline 2 & Content & Speech act & Epistemic & \\
\hline 1 & Content & Epistemic & Speech act & \\
\hline 1 & Content, epistemic & Speech act & & \\
\hline 2 & Speech act & & & Content, epistemic \\
\hline 2 & Speech act & Epistemic & Content & \\
\hline 1 & Speech act & Content & Epistemic & \\
\hline
\end{tabular}

$\begin{array}{ll}\text { Mother: } & \text { Voorzichtig. } \\ & \text { 'Be careful.' }\end{array}$

Child: $\quad J a$, want dan gaat 'ie stuk.

(Hein, 2;8.28)

'Yes, because then [meaning: otherwise] it will break.'

Hij (i)s een meisje volgens mij. Want ik ben zusje \# van Lotte.

(Abel, 3;1.7)

'He (i)s a girl, I think. Because I am (a) sister of Lotte.'

Section 5.1 presents an overall picture of the domain development. Here we focus on the question whether children are able to produce connectives in all three domains. Section 5.2 introduces the development per causal connective, indicating whether children - once they are able to use the three domains - adhere to the domain preferences typical of adult connective use. Section 5.3 presents a summary of the longitudinal results.

\subsection{General picture of the domain developments}

As a first start, we compared the Dutch data to the English data mentioned in KGE. Since Kyratzis and colleagues do not provide individual developmental patterns, but present their domain data per age group, we also grouped the data of the twelve Dutch children. To be more precise, we determined the total frequencies of use in the different domains till the age of $3 ; 6$, the upper age boundary of the youngest age group in the English study. Table 6 presents a comparison of our distribution results for Dutch and the English frequencies (see also the data in Table 1, taken from KGE, p. 209).

Table 6 shows that the Dutch children - just like the English children - produced a large number of uninterpretable utterances. This category of uninterpretable fragments included incomplete utterances, utterances that contained inaudible parts of speech, and fragments in which the two related clauses could not be linked in a sensible way.

In addition, Table 6 shows that Dutch children as young as three were able to produce connectives in all three domains. This contrasts with the English study, in which neither content nor epistemic fragments were found. This suggests that the Dutch data were probably collected in a larger variety of conversational contexts than the English data.

We also determined the acquisition order of the domains per child. An overview of these individual orders of emergence can be found in Table 7.

A quick count shows that seven children produced content first, and five children produced speech act first. Only one child, Abel, came up with two domains at the same time: The first file in which he used want 'because' contained both a content fragment and an epistemic fragment. Although some children had a very infrequent use of connectives, these individual data imply that the relative order of content and speech act cannot be established on the basis of these corpus findings. A clear conclusion is that epistemic is never acquired first.

\subsection{Domains in the acquisition of four Dutch causal connectives}

The Dutch connectives differ in the time at which they enter into the child's language. This can be seen in Table 8, which presents an overview of the ages of first emergence of the four causal connectives. This table shows that during the recording periods want is produced by all children but one, whereas omdat and daarom show up in the data of four children and dus is used as a causal connective by just two children.

Looking at individual connectives, we can say that five children were able to produce want in all three domains (see Table 9). 
Table 8

Overview of ages of first emergence of the four causal connectives.

\begin{tabular}{|c|c|c|c|c|}
\hline Child & want & omdat & daarom & dus \\
\hline Abel & $2 ; 10.0$ & - & - & - \\
\hline Daan & $3 ; 1.14$ & - & - & - \\
\hline Hein & $2 ; 8.28$ & $2 ; 10.15$ & $2 ; 10.24$ & - \\
\hline Iris & $3 ; 2.11$ & - & - & - \\
\hline Josse & $3 ; 0.20$ & $2 ; 11.23$ & $2 ; 11.23$ & - \\
\hline Laura & $3 ; 4.25$ & $5 ; 1.21$ & - & $4 ; 0.20$ \\
\hline Matthijs & $2 ; 11.19$ & - & - & - \\
\hline Niek & - & - & $3 ; 9.6$ & - \\
\hline Peter & $2 ; 8.22$ & - & - & - \\
\hline Sarah & $2 ; 9.7$ & $3 ; 3.21$ & $4 ; 0.11$ & $4 ; 0.11$ \\
\hline Thomas & $2 ; 10.19$ & - & - & - \\
\hline Tomas & $2 ; 10.10$ & - & - & - \\
\hline
\end{tabular}

Table 9

Want: distribution over the three domains of use.

\begin{tabular}{|c|c|c|c|c|c|}
\hline Child & Content & Epistemic & Speech act & Uninterpretable & Total \\
\hline Abel & 6 & 7 & 8 & 6 & 27 \\
\hline Daan & 0 & 1 & 1 & 0 & 2 \\
\hline Hein & 0 & 1 & 1 & 0 & 2 \\
\hline Iris & 0 & 0 & 1 & 0 & 1 \\
\hline Josse & 2 & 6 & 4 & 9 & 21 \\
\hline Laura & 5 & 2 & 4 & 4 & 15 \\
\hline Matthijs & 4 & 3 & 13 & 21 & 41 \\
\hline Niek & 0 & 0 & 0 & 0 & 0 \\
\hline Peter & 1 & 0 & 0 & 2 & 3 \\
\hline Sarah & 22 & 40 & 32 & 29 & 123 \\
\hline Thomas & 0 & 1 & 1 & 2 & 4 \\
\hline Tomas & 1 & 0 & 0 & 0 & 1 \\
\hline
\end{tabular}

Table 10

Frequencies of want and omdat in Laura's data.

\begin{tabular}{|c|c|c|c|c|}
\hline Age & Content & Epistemic & Speech act & Uninterpretable \\
\hline $3 ; 4.25$ & 1 want & - & - & - \\
\hline $4 ; 1.11$ & 1 want & - & - & - \\
\hline $4 ; 5.9$ & - & - & - & 1 want \\
\hline $4 ; 7.31$ & - & - & - & 1 want \\
\hline $4 ; 8.28$ & - & - & 1 want & 1 want \\
\hline $4 ; 9.10$ & - & - & 1 want & - \\
\hline $4 ; 10.2$ & 1 want & - & - & - \\
\hline $5 ; 0.20$ & - & - & 1 want & - \\
\hline $5 ; 1.21$ & 2 want, 1 omdat & - & - & 1 want \\
\hline $5 ; 2.12$ & 4 omdat & 2 want, 2 omdat & 1 want, 3 omdat & - \\
\hline $5 ; 6.12$ & 2 daaromdat & - & - & \\
\hline Total & 13 & 4 & 7 & 4 \\
\hline
\end{tabular}

Daan, Hein, Iris, Niek, Peter, Thomas, and Tomas use want very infrequently. For this reason, the data of these seven children are not suitable to draw conclusions on the development of the three domains of use. For the other five children, who produce want more frequently, an overview like the following one for Laura was constructed (see Table 10). ${ }^{7}$

Table 10 reveals that Laura has a clear order in her acquisition of the three domains: the content use of want emerges first, then the speech-act use appears, and finally the epistemic use of want emerges. Laura is remarkable in this respect, since the other four children do not show a clear preference for one of the domains during their first recordings. The earliest wantfragments produced by Abel, Josse, Matthijs, and Sarah provide examples from all three domains. These children differ from each other in that Josse and Sarah have a slight preference for the epistemic domain, whereas Matthijs prefers to use want in speech-act fragments, and Abel has no domain preference at all (compare the overall frequencies in Table 9). All in all, the data for want do not allow us to infer a general order in which the three domains emerge in child language.

\footnotetext{
${ }^{7}$ In Table 10 the recording dates without want- or omdat-fragments are disregarded.
} 
Table 11

Omdat: distribution over the three domains of use.

\begin{tabular}{lllr}
\hline Child & Content & Epistemic & Speech act \\
\hline Hein & 4 & 1 & 2 \\
Josse & 2 & 1 & 4 \\
Laura & 7 (daar)omdat & 2 & 3 \\
Sarah & 9 (daar)omdat & 0 & 1 \\
\hline
\end{tabular}

The domain analyses of omdat shows that only four children used omdat in a correct and creative way. Two of these children, Hein and Josse, only used omdat when they answered why-questions. These why-questions mostly prompted content relations (as in (22)) or speech-act relations (as in (23)).

$$
\text { Mother: Waarom wil jij mij niet helpen? }
$$

Child: $\quad$ Omdat ik niet zin heb.

$$
\begin{array}{ll}
\text { Child: } \quad \text { Je mag niet meer zingen. } & \text { 'You may not sing anymore.' }
\end{array}
$$

Adult: $\quad$ Nee, waarom niet?

'No, why not?'

Child: $\quad$ Omdat ik niet leuk vind.

(Josse, 3;2.15)

'Because I don't like it.'

The other two children, Laura and Sarah, produced omdat spontaneously most of the time (see (24) for a content example). Their omdat-use was remarkable in another respect: they came up with the same combination of daarom and omdat: daarom-dat (see (25)-(27)). ${ }^{8}$ Laura produced this form two times, but Sarah consistently used daar-om-dat instead of omdat. This form also occurred once in the data of Abel (see (28)).

(24) Dit is xxx natte kleren, omdat ik in 't zwembad gezeten heb.

(Laura, 5;2.12)

'This is xxx wet clothes, because I have been in the swimming pool.'

(Laura is talking to herself during her play.)

Waarom heb je mij spullen gepikt! Daar-om-dat jij zo veel had.

'Why did you steal my things? Because you had so many of them.'

Daar-om-dat ik vier geworden ben, daarom kan ik deze.

(Sarah, 4;0.11)

'Because I turned four, that's why I can make this one.'

Mother: Eh, waarom wil je chocomelk?

'Er, why do you want chocolate milk?'

Child: Daar-om-dat ik veel dorst heb.

(Sarah, 4;0.11)

'Because I am very thirsty.'

(Abel just recovered from an infection in his finger.)

Adult: $\quad$ Maar hoe kwam dat dan, die infectie?

'But how did you get that infection?'

Child: Daar-om-dat in de auto komt.

(Abel, 2:10.14)

'Because it came in the car.'

Table 11 shows the distributions of omdat over the three domains. It appears that omdat is hardly used in the epistemic domain. With respect to the other two domains, the children show variation. Sarah has a clear and Laura a slight preference for (daar)omdat in the content domain, although Sarah's very first omdat-clause marks a speech-act relation. Hein and Josse do not show such a clear preference for one of the domains. To conclude, the data for omdat do not allow us to infer a general order in which the three domains emerge in child language. This finding is partly due to the very low number of

\footnotetext{
${ }^{8}$ Unfortunately, these utterances do not allow us to conclude whether the child is indeed conflating daarom and omdat, or that it combines daarom with the complementizer dat 'that'. Because omdat would be the most appropriate connective here, we have chosen to classify these connective combinations as instances of omdat.
} 
omdat-clauses in the data of these young children. However, the two children who do have a domain preference in their use of omdat reflect the prototypical content use that adults exhibit.

The word dus 'so' only appears as a causal connective in the data of Laura and Sarah. Both girls have a clear domain preference: all their connective fragments are instances of epistemic relations (cf. (29)-(31)). This is in accordance with Stukker's (2005) findings that dus has a strong preference for use in the epistemic domain.

$$
\begin{aligned}
& \text { Het (= Laura's schoenen) is groot, dus ik ben al zoveel jaar. } \\
& \text { 'It (= Laura's shoes) is big, so I am that many years.' } \\
& \text { Mother: Ja, het zijn een hele hoop druiven. } \\
& \text { 'Yes, there are a lot of grapes.' } \\
& \text { Child: Dus die krijg je niet allemaal op. } \\
& \text { 'So you cannot eat all of them.' }
\end{aligned}
$$

(Laura, 4;0.20)

(Sarah 4;5.29)

(Sarah 4;5.29)

The lexical item dus occurs in the data of Abel, Matthijs, Thomas and Thomas as well, but in these cases the dus-clause is either uninterpretable, or dus seems to be used as a kind of filler. In the latter case, dus either occurs as a single word proposition, or at the end of a clause, preceded by a short pause (as in (32)). Similarly, daarom 'that's why' is very infrequent in child language: Hein and Josse use it only once as a causal connective, Niek produces it twice, and Sarah comes up with an interpretable daarom eight times. There are more children who produce daarom, but they either use it in incomprehensible clauses or they use it as a bromide (as in (33)). This bromide function of daarom occurs in the data of Abel, Daan, Laura, Matthijs, Niek, Sarah and Tomas.

$$
\begin{aligned}
& \text { Daar moet de chauffeur in. Hier is de dierentuin, dus. } \\
& \text { 'The driver has to go in there. Here is the zoo, so.' } \\
& \text { Child: } \quad \text { Niet doen! } \\
& \text { 'Don't do that!' } \\
& \text { Adult: Warom niet? } \\
& \text { 'Why not?' } \\
& \text { Child: Daarom niet. }
\end{aligned}
$$$$
\text { (Matthijs 3;6.3) }
$$

(Tomas, $3 ; 1.2$ )

'Just because.'

The majority of the daarom-clauses are instances of a causal relation in the content domain (cf. (34)). There is one example in which daarom marks a speech-act relation (see (35)).

$$
\begin{array}{ll}
\text { Child: } & \text { Want jij heb em (= een puzzel) nooit meer gedaan, hè. } \\
& \text { 'Because you didn't do it (= a puzzle) for a long time, did you?' } \\
\text { Mother: } & \text { Nee. } \\
& \text { 'No.' } \\
\text { Child: } & \text { Daarom weet je em niet zo goed. } \\
& \text { 'That's why you cannot do it (lit. him) so well.' }
\end{array}
$$$$
\text { (Sarah, 4;9.29) }
$$

Ik ga eh alleen (pro)beren. Daarom mag Pepijn niet kijken.

(Hein, $2 ; 10.24)$

'I'm gonna er try it on my own. That's why Pepijn is not allowed to watch.'

Although daarom is relatively rare in child language, it can be concluded that children have a preference for daarom as a marker of content relations. Again, this fits in with previous observations that daarom is a content-oriented causal connective (cf. Stukker, 2005).

\subsection{Summary of the longitudinal domain results}

The grouped longitudinal data in section 5.1 showed that Dutch children as young as three were able to produce connectives in all three domains. This is contrary to the English study by Kyratzis et al. (1990), in which neither content nor epistemic fragments were found for the youngest age group. The orders of emergence per child showed that the relative acquisition order of the content and speech-act domain could not be established on the basis of these recordings. Although some children showed very infrequent use of connectives, we can at least conclude that epistemic was never acquired first. 
The data on the development of the individual connectives did not result in further insight into the order of emergence of the domains. For want and omdat it was not possible to infer a general order in which the three domains emerged in child language, because different children showed different domain preferences, whereas others used the connectives too infrequently or not at all. Two children showed a slight preference for use of omdat in the content domain. Only dus and daarom showed a clear division of labor: dus was only used in epistemic relations, whereas the majority of the daaromclauses were instances of content relations. This reveals that children as young as three notice that different causal connectives may have different domain preferences.

Of course, the results of this longitudinal study need to be treated with care. Context effects may have occurred, because the compilers of the longitudinal corpora - just as in the English study - did not systematically collect their data in descriptive, directive and argumentative contexts. Nevertheless, we were still able to show that both content and epistemic relations occur earlier in child language than Kyratzis et al. (1990) report.

\section{Discussion and conclusion}

Sweetser's (1990) domain theory appears to be an interesting candidate for extending the cumulative complexity approach (Evers-Vermeul and Sanders, 2009) with an additional cognitive primitive, at least for positive causal relations (cf. Sanders et al.'s (1992) Source of Coherence). The distinction between content, epistemic and speech-act relations can refine the developmental sequence we find in the acquisition of causal connectives and coherence relations. Recent insights from (cross-linguistic) corpus studies indicate that domain-like distinctions - often defined in terms of Subjectivity - can indeed be taken as cognitive categories (Sanders, 2005; Sanders and Spooren, 2009; Sanders and Sweetser, 2009).

When do children discover the different domain uses of causal connectives? We can conclude that this happens very early. Our experimental studies revealed that even three-year-old children are able to produce causal connectives in all three domains. These results challenge the findings reported in Kyratzis et al. (1990). From our longitudinal study we can conclude that children as young as $2 ; 8$ are able to produce causal connectives in both the content and the speech-act domain, but that the epistemic domain is acquired later.

These findings suggest that the domain distinction is indeed useful for refining the cumulative complexity approach. The least we can say is that developmental trends in this area cannot be described without the distinctions made by the classification (cf. the weak prediction in Spooren and Sanders, 2008:2009). This holds true for all three domains. Furthermore, we can maintain a stronger hypothesis for the epistemic domain versus the other two domains. Epistemic relations are very often based on real-world cause-consequence relations, and can therefore be regarded as more complex than relations in the content domain. This relatively higher complexity is reflected in the order in which epistemic and content relations are acquired. This is in line with the strong prediction in Spooren and Sanders, 2008:2009), which states that relations that are analyzed as simple are acquired before relations that are analyzed as complex.

Both speech-act and content relations are acquired earlier than epistemic relations. This raises the question what these two domains have in common. It has been observed in the literature (Martin, 1992; Verstraete, 1998; Dancygier and Sweetser, 2005; Sanders et al., 2009) that explicating speech acts turns speech-act relations into content relations. For example, the a-clause in (36), with the implicit imperative, can be seen as a speech-act relation. The b-variant, however, is considered a content relation: the reason why the speaker conducts a volitional action (forbid) is provided in the second clause.

$$
\begin{aligned}
& \text { a. Don't shout! Because it hurts my ears. } \\
& \text { b. I forbid you to shout, because it hurts my ears. }
\end{aligned}
$$

This observation shows how much speech act and content relations have in common; in fact they also share that they are often tied to speakers in the here and now. The only difference is that speakers - who are responsible for the causal relation are readily available in the speech act situation and therefore remain implicit, whereas in content relations they are mentioned explicitly, because they are not present in the Deictic Center of Communication (à la Bühler, see the notion of Basic Communicative Space in Sanders et al., 2009). Epistemic relations, however, concern implicit and non-transparent speaker's reasoning processes, which may be complex for children to interpret because it is hard to see things from another person's perspective (Zufferey (2007) uses Theory of Mind to explain this same observation). Furthermore, epistemic relations often concern more general issues, and expressing them often requires more, or more abstract world knowledge than uttering relations in the content or speech-act domain. No wonder, then, that children only come up with epistemic relations after they have acquired content and speech-act relations.

The relative complexity of epistemic relations, compared to speech act and content relations, can also be found at other linguistic levels than the interclausal discourse level. For example, Gruber (1975) studied an English girl (aged 1;2-1;4) in her two-word and three-word phase. He concludes that young children start with performatives such as want (have) shoe, I want up, and I no want. Next, they come up with constatives, in which they describe a subject and at least one part of the predication (e.g. daddy crying, shoe all gone) (examples taken from Gruber, 1975:514). This indicates that speech acts and descriptions of states of affairs enter the child language very early, and hence, that the prerequisites for producing speech-act and content relations are met at a very young age. In contrast, reasoning does not play a role at this age. Another indication 
in this area is that communication verbs such as say and ask are acquired before mental state verbs such as think and believe (cf. De Villiers and Pyers, 2002; Zufferey, 2007).

Given that children as young as 2;8 were able to produce connectives in the content and the speech-act domain, and that the number of epistemic relations in the longitudinal corpus may have been deflated due to context effects, the question remains when children start making this domain distinction. What kind of research might shed more light on this development? A first possibility is to look at more dense longitudinal corpora (available for languages such as German and English), using a more sophisticated statistical method. Van Veen et al. (2009), for instance, have shown that growth curve analysis is a fruitful methodology in this area. One method we would rather not recommend is further elicitation experiments with even younger children. Although our experimenters were instructed to refrain from asking why-questions as much as possible, they did use them, or asked how come-questions instead. That children often provided a proper response to these questions indicates that they are indeed capable of producing the relevant relations. However, the fact that the experimenters frequently felt the need to urge children to motivate their utterances shows that the talkativity of even younger children might become a hindrance in observing their abilities in expressing domains linguistically. Therefore, a second option would be - not to look at children's production further - but to analyze children's early comprehension of content, epistemic and speech-act domains. One option in this area (that we are working on as well) would be to conduct eye-tracking experiments.

A third option is to investigate what kind of domain input parents provide their children with, or what type of domains they elicit with their why-questions. This is especially interesting because researchers make different choices in taking in or leaving out children's responses to why-questions when describing the developmental pattern and because parental questions may alter the domain of the causal relation. Researchers who disregard answers to why-questions focus on the development of spontaneously produced causal utterances. Still, children's reactions to why-questions appear to be valuable in their own respect. Our study has shown that children as young as three are able to come up with reasonable answers to why-questions, indicating comprehension of the domain of the causal relation. However, Van Veen et al. (submitted for publication) have shown that very young children do not answer why-questions (properly), and that the appropriateness of their answers improves during their linguistic development. This indicates that taking in children's answers to why-questions may supplement the developmental picture that can be gained from spontaneous utterances. Parental why-questions are interesting from another perspective as well, because their questions may alter the domain of the causal relation. Most of the time, parents simply ask 'why?', only urging the child to present an account for the previous utterance. Sometimes, however, they ask more elaborate why-questions. For example, in (37), Dennis produces a directive. The fact that he produces the explanation only with the investigator's help makes the causal relation ambiguous in terms of what domain it belongs to: it could be a justification of his speech act 'put it here', or it could be an epistemic relation, providing a reason why it is desirable that the sword should go there. It seems promising to investigate children's responses to such questions in more detail.

$$
\begin{array}{ll}
\text { Child: } & \text { Pak de zwaard en leg hem hier. } \\
& \text { 'Take the sword and put it here.' } \\
\text { Investigator: } & \text { En vertel hem maar warom dat dan moet. } \\
& \text { 'And just tell him why he has to.' } \\
\text { Child: } & \text { Anders kan die niet schieten. } \\
& \text { 'Otherwise he cannot shoot.' }
\end{array}
$$

(Dennis, 5;5)

An important conclusion from our acquisition study is that researchers need to be explicit about their operationalizations and that context plays a crucial role in the production of domain types. Our approach of using converging methodologies showed that both longitudinal corpus studies and cross-sectional experiments have their own merits and drawbacks. In fact, we can say that the two methodologies complement each other nicely: corpus-based data show us children's earliest spontaneous use and enable us to track longitudinal developments; experiments enable us to control for context effects. We have shown that specific hypotheses about the use of certain types of relations in specific communicative contexts can be tested successfully in experiments with young children (see sections 3 and 4 ). Supplementing the study of longitudinal corpora with experimental data therefore seems a fruitful methodology in order to shed more light on important issues in the area of discourse and cognition, to which the study of connectives and their acquisition provide a challenging window.

\section{Acknowledgements}

This research was enabled by The Netherlands Organization for Scientific research, through NWO-Vici-grant 277-70-003, awarded to Ted Sanders, and is partly based on Chapter 13 of the Ph.D. dissertation of the first author (Evers-Vermeul, 2005). We would like to thank Arvid van Maaren, Marijke van Middendorp, Annelieke Dekker and Maud Fontein for joining us in conducting the experiments. 


\section{Appendix A. Logit analysis of experiment I}

Table A1

Results logit analysis.

\begin{tabular}{|c|c|c|c|c|c|c|}
\hline Logit (fr) & $\chi^{2}$ model & df & $p$ model & $\chi^{2}$ factor & df & $p$ factor \\
\hline 1. constant & 89.43 & 7 & $<.001$ & - & - & - \\
\hline+2 . age group & 85.79 & 6 & $<.001$ & 3.63 & 1 & $<.1$ \\
\hline+3. task & 78.90 & 5 & $<.001$ & 6.89 & 1 & $<.01$ \\
\hline +4. domain & 76.21 & 4 & $<.001$ & 2.69 & 1 & $<.1$ \\
\hline+5 . task $\times$ domain & 12.71 & 3 & $<.01$ & 63.50 & 1 & $<.001$ \\
\hline+6. group $\times$ task & 6.15 & 2 & $<.05$ & 6.56 & 1 & $<.025$ \\
\hline+7 . group $\times$ domain & 5.59 & 1 & $<.025$ & 0.56 & 1 & $<.9$ \\
\hline+8 group $\times$ task $\times$ domain & 0 & 0 & 1 & 5.59 & 1 & $<.025$ \\
\hline
\end{tabular}

\section{Table A2}

Parameter estimates for model 8.

\begin{tabular}{|c|c|c|c|c|}
\hline Parameter & Estimate & s.e. & $z$-score & $p$ \\
\hline constant & -2.60 & 0.19 & -13.96 & $<.001$ \\
\hline group: group 2 & -0.67 & 0.30 & -2.24 & .03 \\
\hline task: argumentative & -0.99 & 0.35 & -2.87 & .004 \\
\hline domain: epistemic & -1.18 & 0.37 & -3.19 & .001 \\
\hline group $\times$ task: group 2 argumentative & -0.18 & 0.59 & -0.32 & .75 \\
\hline group $\times$ domain: group 2 epistemic & -1.10 & 0.83 & -1.33 & .18 \\
\hline task $\times$ domain: argumentative epistemic & 2.17 & 0.51 & 4.29 & $<.001$ \\
\hline group $\times$ task $\times$ domain: group 2 argumentative epistemic & 2.21 & 1.00 & 2.20 & .03 \\
\hline
\end{tabular}

\section{Appendix B. Logit analysis of experiment II}

Table B1

Results logit analysis.

\begin{tabular}{|c|c|c|c|c|c|c|}
\hline Logit (fr) & $\chi^{2}$ model & df & $p$ model & $\chi^{2}$ factor & df & $p$ factor \\
\hline 1. constant & 562.9 & 17 & $<.001$ & - & - & - \\
\hline+2 . age group & 559.9 & 16 & $<.001$ & 2.9 & 1 & $<.95$ \\
\hline +3. task & 490.8 & 14 & $<.001$ & 69.2 & 2 & $<.001$ \\
\hline +4. domain & 449.3 & 12 & $<.001$ & 41.5 & 2 & $<.001$ \\
\hline+5. task $\times$ domain & 14.3 & 8 & $<.07$ & 435.0 & 8 & $<.001$ \\
\hline
\end{tabular}

Table B2

Parameter estimates for model 5.

\begin{tabular}{|c|c|c|c|c|}
\hline Parameter & Estimate & s.e. & $z$-score & $p$ \\
\hline constant & -1.85 & 0.16 & -11.9 & $<.001$ \\
\hline group: group 2 & 0.26 & 0.14 & 1.86 & .03 \\
\hline task: directive & -2.55 & 0.43 & -5.90 & $<.001$ \\
\hline task: argumentative & -3.25 & 0.59 & -5.47 & $<.001$ \\
\hline domain: speech act & -13.34 & 54.23 & -0.25 & .4 \\
\hline domain: epistemic & -3.25 & 0.59 & -5.51 & $<.001$ \\
\hline task $\times$ domain: directive speech act & 16.87 & 54.23 & 0.31 & .38 \\
\hline task $\times$ domain: directive epistemic & 3.67 & 0.80 & 4.60 & $<.001$ \\
\hline task $\times$ domain: argumentative speech act & 3.25 & 76.69 & 0.04 & .48 \\
\hline task $\times$ domain: argumentative epistemic & 6.11 & 0.84 & 7.24 & $<.001$ \\
\hline
\end{tabular}

\section{References}

Bloom, Lois, Lahey, Margaret, Hood, Lois, Lifter, Karen, Fiess, Kathleen, 1980. Complex sentences: acquisition of syntactic connectives and the semantic relations they encode. Journal of Child Language 7, 235-261 Reprinted in: Bloom, L. (Ed.) 1991. Language Development from Two to Three. Cambridge University Press, Cambridge, pp. 261-289. 
Bloom, Lois, Merkin, Susan, Wootten, Janet, 1982. Wh-questions: linguistic factors that contribute to the sequence of acquisition. Child Development 53, 1084-1092.

Bol, Gerard W., 1996. Optional subjects in Dutch child language. In: Koster, C., Wijnen, F. (Eds.), Proceedings of the Groningen Assembly on Language Acquisition held at the University of Groningen, 7-9 September 1995, Center for Language and Cognition Groningen, Groningen, pp. 125-135.

Braunwald, Susan R., 1997. The development of BECAUSE and SO: Connecting language, thought, and social understanding. In: Costermans, J., Fayol, M. (Eds.), Processing Interclausal Relationships: Studies in the Production and Comprehension of Text. Lawrence Erlbaum Associates, New Jersey, pp. 121137.

Brown, Roger, 1973. A First Language: The Early Stages. Harvard University Press, Cambridge, MA.

Clark, Eve V., 1978. Discovering what words can do. In: Farkas, D., Jacobsen, W.M., Todrys, K.W. (Eds.), Papers from the Parasession on the Lexicon, Chicago Linguistics Society, April 14-15, 1978, Chicago Linguistic Society, University of Chicago, Chicago, pp. 34-57.

Dancygier, Barbara, Sweetser, Eve E., 2005. Mental Spaces in Grammar: Conditional Constructions. Cambridge University Press, Cambridge.

De Villiers, Jill G., Pyers, Jennie E., 2002. Complements to cognition: a longitudinal study of the relationship between complex syntax and false-belief understanding. Cognitive Development 17, 1037-1060.

Diessel, Holger, 2004. The Acquisition of Complex Sentences. Cambridge University Press, Cambridge.

Elbers, Loekie, Wijnen, Frank, 1992. Effort, production skill, and language learning. In: Ferguson, C.A., Menn, L., Stoel-Gammon, C. (Eds.), Phonological Development: Models, Research, Implications. York, Timonium, MD, pp. 337-368.

Evers-Vermeul, Jacqueline, 2005. The Development of Dutch Connectives: Change and Acquisition as Windows on Form-Function Relations. Ph.D. dissertation, Utrecht University, LOT, Utrecht.

Evers-Vermeul, Jacqueline, Sanders, Ted, 2009. The emergence of Dutch connectives; how cumulative cognitive complexity explains the order of acquisition. Journal of Child Language 36 (4), 829-854.

Gruber, Jeffrey S., 1975. Performative-constative transition in child language development. Foundations of Language $12,513-537$.

Hood, Lois, Bloom, Lois, 1979. What, when, and how about why: A longitudinal study of early expressions of causality. Monographs of the Society for Research in Child Development 44 (Serial No. 181).

Klein Gunnewiek, Lisanne, 1999. Acquisition sequence of German: a comparison of cross-sectional versus longitudinal data. In: Don, J., Sanders, T. (Eds.), Utrecht Institute of Linguistics OTS Yearbook 1998-1999. Utrecht Institute of Linguistics OTS, Utrecht, pp. $48-57$.

Kyratzis, Amy, Guo, Jiansheng, Ervin-Tripp, Susan, 1990. Pragmatic conventions influencing children's use of causal constructions in natural discourse. In: Hall, K., Koenig, J.P., Meacham, M., Reinman, S., Sutton, L. (Eds.), Proceedings of the Sixteenth Annual Meeting of the Berkeley Linguistics Society. BLS, Berkeley, CA, pp. 205-214.

MacWhinney, Brian, 2000. The CHILDES Project: Tools for Analyzing Talk, third edition. Lawrence Erlbaum Associates, Mahwah, NJ.

Martin, James R., 1992. English Text: System and Structure. John Benjamins, Amsterdam.

McCabe, Allyssa, Peterson, Carole, 1985. A naturalistic study of the production of causal connectives by children. Journal of Child Language 12 (1), $145-159$.

McCabe, Allyssa, Peterson, Carole, 1997. Meaningful "mistakes": the systematicity of children's connectives in narrative discourse and the social origins of this usage about the past. In: Costermans, J., Fayol, M. (Eds.), Processing Interclausal relationships: Studies in the Production and Comprehension of Text. Lawrence Erlbaum Associates, New Jersey, pp. 139-154.

Piaget, Jean, 1930/1970. The Child's Conception of Physical Causality. Routledge and Kegan Paul, London.

Pit, Mirna, 2003. How to Express Yourself with a Causal Connective. Subjectivity and Causal Connectives in Dutch, German and French. Ph.D. dissertation, Utrecht University, Rodopi, Amsterdam/New York.

Sanders, Ted, 1997. Semantic and pragmatic sources of coherence: On the categorization of coherence relations in context. Discourse Processes $24,119-147$.

Sanders, Ted, 2005. Coherence, causality and cognitive complexity in discourse. In: Aurnague, M., Bras, M., Le Draoulec, A., Vieu, L. (Eds.), Proceedings/Actes SEM-05, First International Symposium on the Exploration and Modelling of Meaning. pp. 105-114.

Sanders, Ted, Sanders, José, Sweetser, Eve, 2009. Causality, cognition and communication: a mental space analysis of subjectivity in causal connectives. In: Sanders, T., Sweetser, E. (Eds.), Causal Categories in Discourse and Cognition. Mouton de Gruyter, Berlin, pp. 19-60.

Sanders, Ted J.M., Spooren, Wilbert P.M., Noordman, Leo G.M., 1992. Toward a taxonomy of coherence relations. Discourse Processes $15,1-35$.

Sanders, Ted, Spooren, Wilbert, 2009. Causal categories in discourse: converging evidence from language use. In: Sanders, T., Sweetser, E. (Eds.), Causal Categories in Discourse and Cognition. Mouton de Gruyter, Berlin, pp. 205-246.

Sanders, Ted J.M., Spooren, Wilbert P.M., Noordman, Leo G.M., 1993. Coherence relations in a cognitive theory of discourse representation. Cognitive Linguistics 4 (2), 93-133.

Sanders, Ted J.M., Sweetser, Eve E., 2009. Causality in language and cognition - what causal connectives and causal verbs reveal about the way we think. In: Sanders, T., Sweetser, E. (Eds.), Causal Categories in Discourse and Cognition. Mouton de Gruyter, Berlin, pp. 1-19.

Shapiro, Lauren R., Hudson, Judith A., 1997. Coherence and cohesion in children's stories. In: Costermans, J., Fayol, M. (Eds.), Processing Interclausal Relationships: Studies in the Production and Comprehension of Text. Lawrence Erlbaum Associates, New Jersey, pp. 23-48.

Spooren, Wilbert, Sanders, Ted, 2008. The acquisition of coherence relations: on cognitive complexity in discourse. Journal of Pragmatics 40 (12), 20032026.

Stukker, Ninke, 2005. Causality Marking across Levels of Language Structure: A Cognitive Linguistic Approach. Ph.D. dissertation, Utrecht University, LOT, Utrecht.

Sweetser, Eve E., 1990. From Etymology to Pragmatics. Metaphorical and Cultural Aspects of Semantic Structure. Cambridge University Press, Cambridge.

Taboada, Maite, Mann, William, 2006. Applications of rhetorical structure theory. Discourse Studies 8 (4), $567-588$.

Van Kampen, Jacqueline, 1997. First Steps in Wh-Movement. Ph.D. dissertation Utrecht University, Utrecht.

Van Veen, Rosie, Evers-Vermeul, Jacqueline, Sanders, Ted, Van den Bergh, Huub, 2009. Parental input and connective acquisition in German; a growth-curve analysis. First Language 29 (3), 267-289.

Van Veen, Rosie, Evers-Vermeul, Jacqueline, Van den Bergh, Huub, Sanders, Ted. “Why? Because!” Parental scaffolding of English and Dutch connective acquisition, submitted for publication.

Verstraete, Jean-Christoph, 1998. A semiotic model for the description of levels in conjunction: external, internal-modal and internal-speech functional. Functions of Language 5 (2), 179-211.

Wing, Clara S., Scholnick, Ellin K., 1981. Children's comprehension of pragmatic concepts expressed in 'because', 'although', 'if and ‘unless'. Journal of Child Language 8, 347-365.

Zufferey, Sandrine, 2007. Pragmatique Lexicale et Métareprésentation. Étude Théorique et Empirique de l'Utilisation et de l'Acquisition des Connecteurs Pragmatiques. Ph.D. dissertation University of Geneva, Geneva.

Jacqueline Evers-Vermeul (born 1973, Ph.D. Utrecht University, 2005) is assistant professor of Dutch language use and discourse studies at Utrecht University, The Netherlands. Her research - at the Utrecht Institute of Linguistics OTS - functions at the interface of language development (both synchronic and diachronic), education, and text quality.

Ted Sanders (born 1963, Ph.D. Tilburg University, 1992) is professor of Dutch language use and discourse studies at Utrecht University, The Netherlands. His group teaches language and communication at several BA- and MA-levels. His research focuses on discourse structure and coherence, from a linguistic and a psycholinguistic perspective. He is the (co-)author of many journal publications and the (co-)editor of several edited books and special issues, see http://www.let. uu.nl/ Ted.Sanders/personal/index.php. 